\title{
The effect of dietary Tenebrio molitor meal inclusion on growth performance and liver health of largemouth bass (Micropterus salmoides)
}

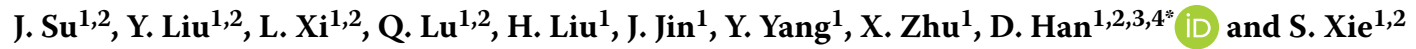 \\ ${ }^{1}$ State Key Laboratory of Freshwater Ecology and Biotechnology, Institute of Hydrobiology, Chinese Academy of Sciences, \\ Wuhan 430072, China P.R.; ${ }^{2}$ University of Chinese Academy of Sciences, Beijing 100049, China P.R.; ${ }^{3}$ Southern Marine \\ Science and Engineering Guangdong Laboratory, Zhanjiang 524025, China P.R.; ${ }^{4}$ Hubei Engineering Research Center for \\ Aquatic Animal Nutrition and Feed, Wuhan 430072, China P.R.; hand21cn@ihb.ac.cn
}

Received: 18 February 2021 / Accepted: 18 November 2021

(c) 2022 Wageningen Academic Publishers

\begin{abstract}
OPEN ACCESS @ (i)
RESEARCH ARTICLE

Abstract

This study investigated the effect of dietary mealworm meal on growth performance, body composition, and liver health of largemouth bass. During the feeding trial, all fish were feed to apparent satiation twice one day for 42 days with 4 experimental diets included $0,10.35,20.70,31.50 \%$ mealworm meal (MWM) replacing graded levels of fishmeal (FM) (0\%, MWM0; 25\%, MWM25; 50\%, MWM50; 75\%, MWM75), respectively. The growth performance (weight gain rate, specific growth rate and feed efficiency) of largemouth bass were significantly decreased in the MWM50, and MWM75 groups. Liver lipogenesis and lipid contents were significantly higher in MWM75 group than in the MWM0 group. In MWM50 and MWM75, the structure of liver tissue was abnormal, and a large number of inflammatory cells infiltrated into the tissue. The transcriptional levels of tumour necrosis factor- $\alpha$, interleukin$1 \beta$, and interleukin-15 were significantly upregulated in MWM75 compared to MWM0. The activity of caspase 3 (casp3) and apoptosis was significantly higher in the MWM75 group than in the MWM0 group. The relative mRNA levels of casp3, casp9, casp8 and casp10 were upregulated in MWM50 and MWM75. It is concluded that MWM can replace $25 \%$ of FM in the diet of largemouth bass without negative effects on growth performance. However, high inclusions of MWM replacing more than 50\% of dietary FM would lead to negative influences on growth and liver health of largemouth bass, partly through enhanced inflammation and apoptosis.
\end{abstract}

Keywords: mealworm meal, growth, inflammation, apoptosis, largemouth bass

\section{Introduction}

With the rapid development of the aquaculture feed industry, the substitution of fishmeal (FM) with other protein sources has gathered interest because of the financial and environmental costs. Edible insects, a conventional food in many countries, are rich in lipid, protein, and minerals depending on the insect species and growth phase (Loh et al., 2020). Insects are mostly omnivorous and can be raised with organic waste while occupying less space, and have a high feed conversion efficiency (Rumpold and Schlüter, 2013a). Therefore, edible insects have great potential as feed protein sources for replacing FM. Various insect species such as black soldier fly (Hermetia illucens), yellow mealworm (Tenebrio molitor), housefly (Musca domestica), silkworm (Bombyx mori) pupae, and superworms (Zophobas morio) have been used as alternative protein sources for cattle, poultry, and swine (Henry et al., 2015; Loh et al., 2020).

Mealworms are an important and common farmed insect protein source for the animal feed industry. A study in mice has proven that feeding with mealworm powder extract was found to improve resistance to several pathogens compared with the control, and the activity of alkaline phosphatase (ALP) was significantly induced by high doses of mealworms (Tang, 2012). According to the literature, mealworms are rich in protein, and fat, chitin, and antimicrobial peptides (Rumpold and Schlüter, 2013b). It has been suggested that low levels of dietary chitin (1\%) 
could enhance the immune response and disease resistance in kelp groupers (Epinephelus bruneus) (Harikrishnan et al., 2012). However, 25\% dietary chitin decreased the growth performance of rainbow trout (Lindsay et al., 1984). Mealworm meal as a replacement for FM has been used in many fish studies (Belforti et al., 2015; Gasco et al., 2016; Henry et al., 2018; Hoffmann et al., 2020; Sankian et al., 2018; Su et al., 2017). Considering growth and feed utilisation, dietary mealworm meal (MWM) can be included up to $14 \%$ of the diet of rainbow trout (Jeong et al., 2020), 20\% for sea trout (Salmo trutta m. trutta) (Hoffmann et al., 2020), and 25\% for European sea bass (Gasco et al., 2016). However, high dietary inclusion of MWM has a negative effect on fish. Dietary inclusion of $50 \%$ MWM has a negative effect on the nutrient digestibility and growth performance of gilthead sea bream (Sparus aurata) (Piccolo et al., 2017). It has also been reported that African catfish (Clarias gariepinus) fed diets with full substitution of MWM exhibited reduced growth performance and nutrient utilisation (Ng et al., 2001). Therefore, the reasons for the negative effects of high dietary inclusion of MWM on fish need to be elucidated.

Largemouth bass (Micropterus salmoides) is increasingly popular in China as a high-value cultured fish. The production of largemouth bass in China has increased annually, reaching nearly 500,000 tons in 2019. Considering the high cost of diets for largemouth bass, the substitution of dietary FM needs to be considered. Mealworm meal as an alternative protein for FM in diets for largemouth bass has not yet been reported. Therefore, in the present study, we evaluated the influence of dietary FM replacement by MWM on growth, feed utilisation, and liver health of largemouth bass. The reasons for negative effects on this species with high dietary inclusions of MWM are sought.

\section{Materials and methods}

All fish used in the present study were managed according to the Guiding Principles for Care and Use of Laboratory Animals and were approved by the Institute of Hydrobiology, Chinese Academy of Science.

\section{Experimental diets}

The formulation of the experimental diets is presented in Table 1. Mealworm meal was purchased from Zehecheng Biotechnology Co., Ltd (Guangzhou, Guangdong, China) and the proximate composition of mealworm is shown in Table 2. Four experimental diets were formulated to include $0,10.35,20.70$, and $31.50 \%$ of MWM to replace 0\% (MWM0), 25\% (MWM25), 50\% (MWM50), and 75\% (MWM75) of FM, respectively. MWM0 was used as the control diet. All the diets were made in puffing feed and the extruded diets were processed through an extruder (TSE65S; Modern Yanggong Machinery S\&T Development Co., Ltd., Beijing, China). All wet diets were oven-dried at $60{ }^{\circ} \mathrm{C}$, and stored at $4{ }^{\circ} \mathrm{C}$.

\section{Fish and feeding trial}

Largemouth bass were purchased from a fish farm (Ezhou, Hubei, China). All fish were cultured in an experimental system with a MWM0 diet for two weeks to adapt to the rearing conditions. The experimental system was an indoor circulating water system with 12 circular plastic tanks (140 l of water). During the whole trial, the water temperature was maintained at $29.0 \pm 1.0^{\circ} \mathrm{C}$. Water dissolved oxygen content was maintained at $6.4 \pm 0.5 \mathrm{mg} / \mathrm{l}$, and ammonia-N lower than $0.5 \mathrm{mg} / \mathrm{l}$. The photoperiod was $12 \mathrm{~h}$ light: $12 \mathrm{~h}$ dark, with a light period from 08:00 to 20:00.

Before the trial, all fish were fasted for $24 \mathrm{~h}$ for gastric emptying. Then, 20 similar-sized largemouth bass (initial weight: $16.06 \pm 0.10 \mathrm{~g}$ ) were randomly selected, weighed, and placed in each tank. Three tanks were randomly selected for each experimental diet. During the experiment, fish were fed to apparent satiation (each feeding lasted approximately $1 \mathrm{~h}$ ) twice a day (09:00 and 16:00) and daily feed intake was recorded. The uneaten feed was removed and recorded. The feeding trial lasted for six weeks.

\section{Sample collection}

At the end of the experiment, after fasting for $24 \mathrm{~h}$, all fish from each tank were weighed to calculate the growth performance. Six fish from each tank were randomly selected and anaesthetised with MS-222 (60 mg/l; Sigma, St. Louis, MO, USA), three fish were weighed and stored at $-20{ }^{\circ} \mathrm{C}$ for body composition analysis, and blood samples were collected from the tail vein of the other three largemouth bass using syringes rinsed with heparin sodium $(0.2 \%)$. After centrifugation at $3,000 \times g\left(4{ }^{\circ} \mathrm{C}\right)$ for $10 \mathrm{~min}$, plasma samples were collected, and immediately frozen, and stored at $-80{ }^{\circ} \mathrm{C}$ until analysis. After blood sampling, the liver, anterior intestine, and pyloric caecum were immediately removed and placed on ice. Pyloric caecum and most of the liver samples were frozen in liquid nitrogen and stored at $-80{ }^{\circ} \mathrm{C}$ for subsequent analysis. The proximal intestine and part of the liver were stored in $4 \%$ paraformaldehyde at $4{ }^{\circ} \mathrm{C}$ for histological analysis. Three fish were randomly selected from each tank to measure their body weight and length. The viscera and liver were taken from the fish and weighed to calculate the viscerosomatic index (VSI), hepatosomatic index (HSI), and condition factor (CF). The liver was collected and stored at $-20{ }^{\circ} \mathrm{C}$ to determine fat content. 
Table 1. Formulation and proximate composition of the experimental diets for largemouth bass.

\begin{tabular}{|c|c|c|c|c|}
\hline & \multicolumn{4}{|c|}{ Experimental diets } \\
\hline & MWMO & MWM25 & MWM50 & MWM75 \\
\hline \multicolumn{5}{|l|}{ Ingredients (g/100 g diet) } \\
\hline Fish meal ${ }^{1}$ & 40 & 30 & 20 & 10 \\
\hline Blood meal ${ }^{2}$ & 4 & 4 & 4 & 4 \\
\hline Gluten $^{3}$ & 5 & 5 & 5 & 5 \\
\hline Soybean meal ${ }^{4}$ & 10 & 10 & 10 & 10 \\
\hline Soybean protein concentrate ${ }^{5}$ & 13 & 13 & 13 & 13 \\
\hline Mealworm meal ${ }^{6}$ & 0 & 10.35 & 20.70 & 31.05 \\
\hline Cassava starch ${ }^{7}$ & 14 & 14 & 14 & 14 \\
\hline Fish oil ${ }^{8}$ & 3.50 & 3.74 & 3.97 & 4.20 \\
\hline Soybean oil & 3.50 & 3.74 & 3.97 & 4.20 \\
\hline Vitamin and mineral additives ${ }^{9}$ & 1 & 1 & 1 & 1 \\
\hline Monocalcium phosphate & 1.50 & 1.50 & 1.50 & 1.50 \\
\hline Choline chloride & 0.10 & 0.10 & 0.10 & 0.10 \\
\hline Microcrystalline cellulose & 4.40 & 3.57 & 2.76 & 1.95 \\
\hline \multicolumn{5}{|c|}{ Proximate chemical composition (g/100 g dry matter) } \\
\hline Crude protein & 51.06 & 51.37 & 51.76 & 52.40 \\
\hline Crude lipid & 8.78 & 8.39 & 8.35 & 8.21 \\
\hline \multicolumn{5}{|c|}{${ }^{1}$ Fish meal: from Superprime, TASA Fish Product Co. Ltd, Peru. } \\
\hline \multicolumn{5}{|c|}{${ }^{2}$ Blood meal: from Beijing Yangyuan Veterinary Medicine Technology Co., Ltd, Beijing, China. } \\
\hline \multicolumn{5}{|c|}{${ }^{3}$ Gluten: from Henan Midaner Trading Co., Ltd, Xinzheng, Henan, China. } \\
\hline \multicolumn{5}{|c|}{${ }^{4}$ Soybean meal: from Qingdao Bohai Agricultural Development Co., Ltd, Qingdao, China. } \\
\hline \multicolumn{5}{|c|}{${ }^{5}$ Soybean protein concentrate: from Yihai grain and oil industry Co., Ltd, Taizhou, Jiangsu, China. } \\
\hline \multicolumn{5}{|c|}{${ }^{6}$ Mealworm meal: from Guangdong Zehecheng Biotechnology Co., Ltd, Guangzhou, China. } \\
\hline \multicolumn{5}{|c|}{${ }^{7}$ Cassava starch: from Wuhan Yiteng Starch Co., Ltd, Wuhan, China. } \\
\hline \multicolumn{5}{|c|}{${ }^{8}$ Fish oil: Peru anchovy oil, purchased from Coland Feed Co., Ltd., Wuhan, China. } \\
\hline${ }^{9}$ Vitamin and mineral additives: from $C$ & up, Guang & & & \\
\hline
\end{tabular}

\section{Table 2. Proximate chemical composition of mealworm meals} used in experimental diets.

$\begin{array}{lr}\text { Proximate chemical composition (\%) } \\ \\ \text { Moisture } & 12.0 \\ \text { Crude protein } & 65.0 \\ \text { Crude lipid } & 3.8 \\ \text { Crude fibre } & 1.0 \\ \text { Ash } & 10.0 \\ \text { Lysine } & 4.8 \\ \text { Methionine } & 1.1 \\ \text { Tryptophan } & 0.7 \\ \text { Threonine } & 2.8\end{array}$

\section{Biochemical analysis}

Proximate compositions of the diets and fish samples were determined according to AOAC methods (AOAC, 2003). Crude protein content was measured according to the Kjeldahl method using a Kjeltec system (Kjeltec-8400, FOSS Tecator, Haganas, Sweden). The Soxhlet extraction technique was used to determine the crude lipid content using a Soxhlet extractor (Soxtec-2055, FOSS Tecator). The ash of fish samples was measured by incineration in a muffle furnace (muffle furnace, Yingshan, Hubei, China) at $550{ }^{\circ} \mathrm{C}$ for $12 \mathrm{~h}$. Chloroform/methanol $(v / v, 2: 1)$ extraction technique was used to measure the lipid content of the liver samples.

Pepsin activity of the pyloric caecum was determined according to the instructions of the commercial kits (Nanjing Jiancheng Bioengineering Institute, Nanjing, Jiangsu, China). The hepatic Fatty acid synthase (FAS) and Acetyl-CoA carboxylase (ACC) contents were measured by ELISA kits (Nanjing Jiancheng Bioengineering Institute). The activity of caspase 3 in the liver was measured using a commercial kit (Beyotime Biotechnology, Shanghai, China). Glucose, total protein, ALP, glutamic-oxaloacetic transaminase (AST), and glutamic-pyruvic transaminase 
(ALT) were determined using an automatic biochemical analyser (Mindray BS-460, Shenzhen, China). Plasma nonesterified fatty acid (NEFA) content was measured following the instructions of a commercial assay kit (Wako Pure Chemical Industries Ltd., Japan).

\section{Histological analysis}

In order to observe the pathological changes in the liver and proximal intestine, the liver and intestine was taken from six fish from each treatment and fixed with $4 \%$ paraformaldehyde, embedded in paraffin, and cut into 4 $\mu \mathrm{m}$ sections. The sections were stained with haematoxylineosin (H\&E) to observe the histopathological changes in the liver and gut. The terminal deoxynucleotidyl transferase dUTP nick end labelling (TUNEL) technique was adopted according to the method of Lu et al. (2019). Normal cell nuclei showed blue fluorescence, and apoptotic cell nuclei showed green fluorescence. The relative area (\%) of apoptotic nuclei was calculated using Image-Pro Plus 6.0 (Media Cybernetics, Houston, TX, USA), apoptotic rate $(100 \%)=$ green area/blue area $\times 100 \%$.

\section{Gene expression analysis}

Total RNA from the liver was extracted with TRIzol reagent (Ambion, Life Technologies, Carlsbad, CA, USA), according to the manufacturer's instructions. The M-MLV First-Strand Synthesis Kit (Invitrogen, Shanghai, China) was used to obtain cDNA by reversing the transcription of total RNA. Real-time PCR was carried out with the LightCycle ${ }^{\circ} 480$ II system using LightCycle 480 SYBR Green I Master Mix (Roche, Basel, Switzerland). The reactions of real-time PCR were based on those described by Su et al. (2020). In the present study, 18 s and elongation factor $1 \alpha($ ef1a) were chosen as internal references for normalisation. The primers for efla, peroxisome proliferator activated receptor $\alpha$ (ppar $\alpha)$, peroxisome proliferator activated receptor $\beta$ (ppar $\beta)$, peroxisome proliferator activated receptor $\gamma$ (ppary), tumour necrosis factor- $\alpha(\operatorname{tnf}-\alpha)$, transforming growth factor $\beta 1$ (tgf- $\beta 1)$, interleukin- $1 \beta$ $(i l-1 \beta)$, interleukin-8 $(i l-8)$, interleukin-11 $\beta(i l-11 \beta)$, interleukin-10 (il-10), interleukin-15 (il-15), caspase-3 (casp3), caspase 8 (casp8), caspase 9 (casp9), and caspase 10 (casp10) were based on Yu et al. (2018). The primers for $18 s$ were based on Sun et al. (2019). The primers for carnitine palmitoyl transferase 1 (cpt1) were based on Xie et al. (2020). The primers for acetyl-CoA carboxylase (acc), fatty acid synthase ( $f a s n)$, sterol regulatory element binding protein 1 (srebf1) were obtained from Yu et al. (2019). The results were calculated using the method described by Bustin et al. (2009). The primer sequences are shown in Table 3.
Table 3. Primers used in the present experiment.

\begin{tabular}{|c|c|c|}
\hline $\begin{array}{l}\text { Gene } \\
\text { name }^{1}\end{array}$ & Primer sequence & Sources \\
\hline $18 s \mathrm{~F}$ & CGGCTACCACATCCAAGGAA & Sun et al. (2019) \\
\hline $18 s \mathrm{R}$ & CCTGTATTGTTATTTTTTCGTCACTACCT & \\
\hline ef1a F & TGCTGCTGGTGTTGGTGAGTT & Yu et al. (2018) \\
\hline ef1a $R$ & TTCTGGCTGTAAGGGGGCTC & \\
\hline $\operatorname{cpt1} \mathrm{F}$ & GATGTTTTATGACGGGCGG & Xie et al. (2020) \\
\hline cpt1 R & TAGGTTTCACGAGCATTGGC & \\
\hline ppara $\mathrm{F}$ & CCACCGCAATGGTCGATATG & Yu et al. (2018) \\
\hline ppara $\mathrm{R}$ & TGCTGTTGATGGACTGGGAAA & \\
\hline pparß F & AGCACCTCGCCATTTGTAATCT & Yu et al. (2018) \\
\hline ppar $\beta$ R & GGACCCCAATCTCCTTCGTC & \\
\hline ppary F & CCTGTGAGGGCTGTAAGGGTTT & Yu et al. (2018) \\
\hline ppary $\mathrm{R}$ & TTGTTGCGGGACTTCTTGTGA & \\
\hline $\operatorname{acc} \mathrm{F}$ & ATCССTCTTTGССАСTGTTG & Yu et al. (2019) \\
\hline $\operatorname{acc} \mathrm{R}$ & GAGGTGATGTTGCTCGCATA & \\
\hline fasn $\mathrm{F}$ & TGTGGTGCTGAACTCTCTGG & Yu et al. (2019) \\
\hline fasn $\mathrm{R}$ & CATGCCTAGTGGGGAGTTGT & \\
\hline srebf1 $\mathrm{F}$ & AGTCTGAGCTACAGCGACAAGG & Yu et al. (2019) \\
\hline srebf1 R & TCATCACCAACAGGAGGTCACA & \\
\hline $\operatorname{tnf}-\alpha \mathrm{F}$ & CTTCGTCTACAGCCAGGCATCG & Yu et al. (2018) \\
\hline $\operatorname{tnf}-\alpha \mathrm{R}$ & TTTGGCACACCGACCTCACC & \\
\hline $\operatorname{tg} f-\beta 1 \mathrm{~F}$ & GCTCAAAGAGAGCGAGGATG & Yu et al. (2018) \\
\hline $\operatorname{tgf}-\beta 1 \mathrm{R}$ & TCCTCTACCATTCGCAATCC & \\
\hline$i-1 \beta F$ & CGTGACTGACAGCAAAAAGAGG & Yu et al. (2018) \\
\hline$i l-1 \beta R$ & GATGCCCAGAGCCACAGTTC & \\
\hline il-8 F & CGTTGAACAGACTGGGAGAGATG & Yu et al. (2018) \\
\hline il-8 R & AGTGGGATGGCTTCATTATCTTGT & \\
\hline$i l-11 \beta \mathrm{F}$ & TTCCCAACAGACAGATGAAGAACTC & Yu et al. (2018) \\
\hline$i l-11 \beta R$ & TGCCTGTGTTCAGCCAGTCAA & \\
\hline il-10F & CGGCACAGAAATCCCAGAGC & Yu et al. (2018) \\
\hline il-10 R & CAGCAGGCTCACAAAATAAACATCT & \\
\hline il-15 F & GTATGCTGCTTCTGTGCCTGG & Yu et al. (2018) \\
\hline il-15R & AGCGTCAGATTTCTCAATGGTGT & \\
\hline casp3 F & GCTTCATTCGTCTGTGTTC & Yu et al. (2018) \\
\hline casp3 R & CGAAAAAGTGATGTGAGGTA & \\
\hline casp8 F & GAGACAGACAGCAGACAACCA & Yu et al. (2018) \\
\hline casp8 R & TTCCATTTCAGCAAACACATC & \\
\hline $\operatorname{casp9} \mathrm{F}$ & CTGGAATGCCTTCAGGAGACGGG & Yu et al. (2018) \\
\hline casp9 R & GGGAGGGGCAAGACAACAGGGTG & \\
\hline casp10 F & CAAACCACTCACAGCGTCTACAT & Yu et al. (2018) \\
\hline casp10 R & TGGTTGGTTGAGGACAGAGAGGG & \\
\hline
\end{tabular}

${ }^{1}$ acc $=$ acetyl-CoA carboxylase; $\operatorname{casp} 10=$ caspase 10;; casp3 = caspase 3; casp8 $=$ caspase 8 ; $\operatorname{casp} 9=$ caspase $9 ; \operatorname{cpt} 1=$ carnitine palmitoyl transferase 1 ; ef1 $a$ = elongation factor $1 \alpha$; fasn = fatty acid synthase; il-10 = interleukin-10; il-11 $\beta=$ interleukin-11 $\beta$; il-15 = interleukin-15; il-1 $\beta=$ interleukin- $1 \beta ; i l-8=$ interleukin-8; $p$ par $\alpha=$ peroxisome proliferator activated receptor $\alpha ; p p a r \beta=$ peroxisome proliferator activated receptor $\beta$; ppary = peroxisome proliferator activated receptor $\gamma ;$ srebf $1=$ sterol regulatory element binding protein $1 ; \operatorname{tgf}-\beta 1$ $=$ transforming growth factor- $\beta 1$; tnf- $\alpha=$ tumour necrosis factor- $\alpha$; 


\section{Statistical analysis}

All data were analysed using SPSS 20 (SPSS Inc., Chicago, IL, USA) for Windows. Duncan's multiple range test was used to detect the significance of differences between groups, followed by a one-way analysis of variance (ANOVA). Statistical significance was set at $P<0.05$ and the results are presented as means \pm standard error (SE).

\section{Results}

\section{Growth performance and morphological indices}

The results of growth, feed utilisation and morphological indices of largemouth bass fed experimental diets are shown in Table 4. The final body weight (FBW) of MWM50 and MWM75 was lower $(P<0.05)$ than that of MWM0 and MWM25. The weight gain rate (WGR) of MWM50 and MWM75 was lower $(P<0.05)$ than that of MWM0, while there was no significant difference in WGR between the MWM0 and MWM25 groups. Similar results were found for the other two growth performance indicators of specific growth rate (SGR) and feed efficiency. However, no significant changes $(P>0.05)$ were observed in feeding rate (FR), CF, VSI and HSI of largemouth bass fed different experimental diets.

\section{Body composition and plasma biochemical parameters}

The body crude lipid content exhibited an increased but not significant change $(P>0.05)$ with the increasing inclusion of dietary MWM (Table 5). However, the body ash content of largemouth bass fed with MWM75 was higher than that of the MWM0 group $(P<0.05)$.

Plasma NEFA content was higher $(P<0.05)$ in the MWM75 group than in the MWM0 group (Table 6). However, the activity of ALP, AST, and ALT in plasma were not affected by dietary inclusion of MWM $(P>0.05)$.

\section{Histological analysis of the proximal intestine}

The structures of the proximal intestine in MWM0 and MWM 25 were normal (Figure 1A). The mucous layer was intact, and the epithelium showed no degeneration or sloughing. However, in groups MWM50 and MWM75, the structures of the proximal intestine were mildly incomplete with a small number of exfoliated epithelial cells, as indicated by the black arrows (Figure 1A). In addition, the intestinal villi length and the activity of pyloric caecum pepsin in largemouth bass were not affected by dietary MWM $(P>0.05)$ (Figure 1B and 1C).

Table 4. The effect of dietary inclusion of mealworm meal on growth performance of largemouth bass. ${ }^{1}$

\begin{tabular}{|c|c|c|c|c|}
\hline & \multicolumn{4}{|c|}{ Experimental diets } \\
\hline & MWMO & MWM25 & MWM50 & MWM75 \\
\hline $\mathrm{IBW}^{2}(\mathrm{~g})$ & $16.09 \pm 0.09$ & $16.03 \pm 0.03$ & $16.02 \pm 0.05$ & $16.09 \pm 0.05$ \\
\hline $\mathrm{FBW}^{3}(\mathrm{~g})$ & $46.42 \pm 0.39^{a}$ & $43.97 \pm 0.95^{\mathrm{a}}$ & $39.64 \pm 1.11^{b}$ & $33.48 \pm 0.16^{c}$ \\
\hline $\mathrm{FR}^{4}(\% \mathrm{BW} / \mathrm{d})$ & $1.89 \pm 0.01$ & $1.89 \pm 0.03$ & $1.91 \pm 0.06$ & $1.93 \pm 0.03$ \\
\hline $\mathrm{FE}^{5}(\%)$ & $122.39 \pm 1.82^{\mathrm{a}}$ & $117.49 \pm 2.69^{a}$ & $105.74 \pm 2.94^{b}$ & $86.87 \pm 1.08^{c}$ \\
\hline WGR $^{6}(\%)$ & $188.55 \pm 4.06^{\mathrm{a}}$ & $174.31 \pm 6.34^{a}$ & $147.39 \pm 6.14^{b}$ & $108.06 \pm 0.95^{c}$ \\
\hline $\mathrm{SGR}^{7}(\% / \mathrm{d})$ & $2.52 \pm 0.03^{a}$ & $2.40 \pm 0.06^{a}$ & $2.15 \pm 0.06^{b}$ & $1.74 \pm 0.01^{c}$ \\
\hline $\mathrm{CF}^{8}\left(\mathrm{~g} / \mathrm{cm}^{3}\right)$ & $2.14 \pm 0.06$ & $2.12 \pm 0.06$ & $2.22 \pm 0.09$ & $2.25 \pm 0.06$ \\
\hline $\mathrm{VSI}^{9}(\%)$ & $8.04 \pm 0.45$ & $8.38 \pm 0.59$ & $9.26 \pm 0.55$ & $8.12 \pm 0.29$ \\
\hline $\mathrm{HSI}^{10}(\%)$ & $2.95 \pm 0.34$ & $3.43 \pm 0.52$ & $3.76 \pm 0.37$ & $2.85 \pm 0.31$ \\
\hline \multicolumn{5}{|c|}{$\begin{array}{l}{ }^{1} \text { Values are means } \pm \text { SE ( } n=3 \text { for calculating FBW, FR, FE, WGR, SGR; } n=9 \text { for calculating CF, VSI, HSI). The different letters in the same row stand for significar } \\
\text { difference }(P<0.05) \text {. }\end{array}$} \\
\hline \multicolumn{5}{|c|}{${ }^{2}$ IBW (g): initial body weight. } \\
\hline \multicolumn{5}{|c|}{${ }^{3}$ FBW (g): Final body weight. } \\
\hline \multicolumn{5}{|c|}{${ }^{4} \mathrm{FR}$ (feeding rate) $(\% \mathrm{BW} / \mathrm{d})=100 \times$ dry feed intake $/($ feeding days $\times(\mathrm{FBW}+\mathrm{IBW}) / 2)$} \\
\hline \multicolumn{5}{|c|}{${ }^{5} \mathrm{FE}$ (feed efficiency) $(\%)=100 \times$ wet weight gain / total amount of the feed consumed. } \\
\hline \multicolumn{5}{|c|}{${ }^{6}$ WGR (weight gain rate) $(\%)=100 \times(F B W-I B W) / I B W}$. \\
\hline \multicolumn{5}{|c|}{${ }^{7}$ SGR (specific growth rate) $(\% / d)=100 \times(\operatorname{Ln}(F B W)-\operatorname{Ln}($ IBW $)) /$ days. } \\
\hline \multicolumn{5}{|c|}{${ }^{8} \mathrm{CF}$ (condition factor) $\left(\mathrm{g} / \mathrm{cm}^{3}\right)=100 \times$ (body weight) $/$ (body length) ${ }^{3}$. } \\
\hline \multicolumn{5}{|c|}{${ }^{9}$ VSI (viscerosomatic index) (\%) = 100 xviscera weight / whole body weight. } \\
\hline${ }^{10} \mathrm{HSI}$ (hepatos & veight / whole bo & & & \\
\hline
\end{tabular}


Table 5. The effect of dietary inclusion of mealworm meal on body composition of largemouth bass. ${ }^{1}$

\begin{tabular}{|c|c|c|c|c|}
\hline & \multicolumn{4}{|c|}{ Experimental diets } \\
\hline & MWMO & MWM25 & MWM50 & MWM75 \\
\hline \multicolumn{5}{|c|}{ Proximate composition (\% dry weight) } \\
\hline Crude protein & $62.38 \pm 1.64$ & $63.13 \pm 1.47$ & $62.35 \pm 1.02$ & $63.29 \pm 0.89$ \\
\hline Crude lipid & $20.28 \pm 1.32$ & $21.41 \pm 1.01$ & $22.83 \pm 0.59$ & $22.64 \pm 0.96$ \\
\hline Ash & $7.61 \pm 0.11^{b}$ & $7.82 \pm 0.12^{\mathrm{ab}}$ & $7.88 \pm 0.23^{a b}$ & $8.30 \pm 0.13^{a}$ \\
\hline
\end{tabular}

Table 6. The effect of dietary inclusion of mealworm meal on plasma biochemical parameters of largemouth bass. ${ }^{1}$

\begin{tabular}{|c|c|c|c|c|}
\hline & \multicolumn{4}{|c|}{ Experimental diets ${ }^{2}$} \\
\hline & MWMO & MWM25 & MWM50 & MWM75 \\
\hline Glucose (mmol/l) & $2.43 \pm 0.80$ & $1.99 \pm 0.38$ & $2.51 \pm 0.34$ & $2.88 \pm 0.55$ \\
\hline $\mathrm{NEFA}(\mathrm{mEq} / \mathrm{l})$ & $0.01 \pm 0.00^{b}$ & $0.04 \pm 0.01^{\mathrm{ab}}$ & $0.05 \pm 0.01^{\mathrm{ab}}$ & $0.08 \pm 0.02^{\mathrm{a}}$ \\
\hline $\mathrm{TP}(\mathrm{g} / \mathrm{l})$ & $28.46 \pm 3.22$ & $27.10 \pm 3.18$ & $28.48 \pm 1.40$ & $25.42 \pm 1.69$ \\
\hline $\mathrm{ALP}(\mathrm{U} / \mathrm{l})$ & $186.29 \pm 38.62$ & $127.97 \pm 9.41$ & $135.94 \pm 16.71$ & $147.64 \pm 23.13$ \\
\hline AST (U/I) & $18.91 \pm 7.27$ & $41.77 \pm 14.32$ & $41.22 \pm 9.41$ & $34.23 \pm 9.07$ \\
\hline ALT (U/I) & $1.97 \pm 0.98$ & $3.22 \pm 0.67$ & $3.37 \pm 0.79$ & $4.92 \pm 1.95$ \\
\hline
\end{tabular}

${ }^{1}$ Values are means $\pm S E(n=6)$. The different letters in the same row stand for significant difference $(P<0.05)$.

${ }^{2} \mathrm{ALP}=$ alkaline phosphatase $; \mathrm{ALT}=$ glutamic-pyruvic transaminase; $\mathrm{AST}=$ glutamic-oxaloacetic transaminase; $\mathrm{NEFA}=$ non-esterified fatty acid; $\mathrm{TP}=$ total protein .
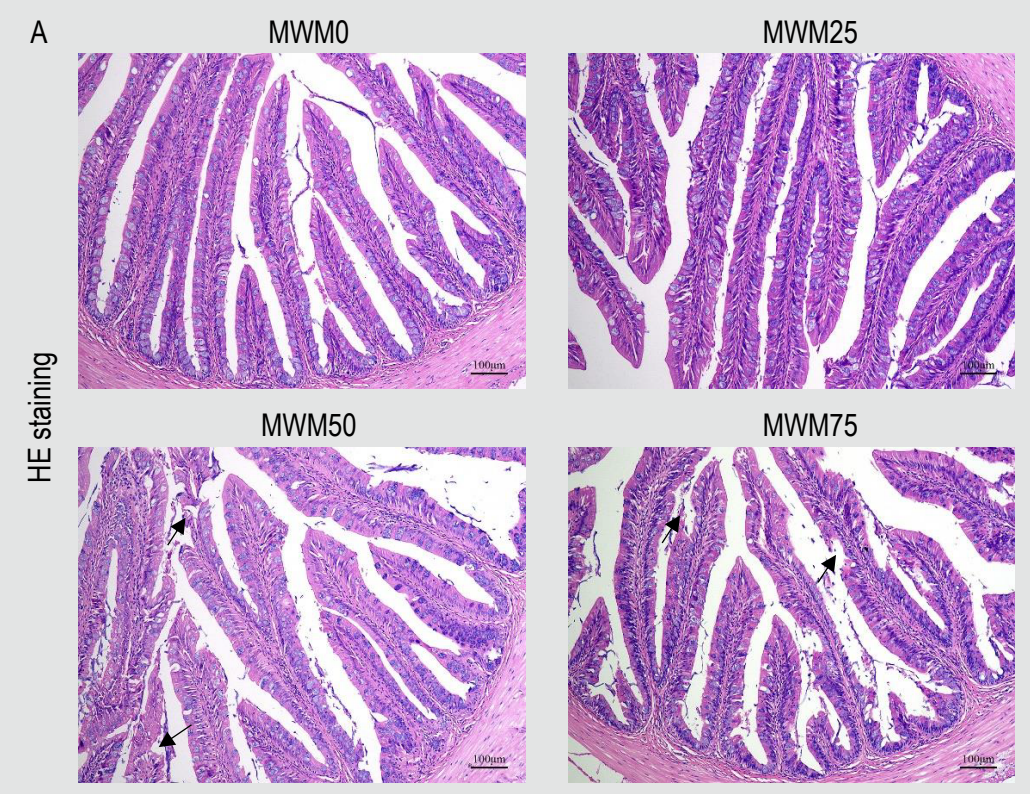

Figure 1. The histology of proximal intestine and pepsin activity of pyloric caecum of largemouth bass fed diets containing graded levels of mealworm meals (MWM). (A) haematoxylin-eosin (H\&E) staining of proximal intestine; the black arrows show the incomplete intestine and exfoliated epithelial cells. 
B

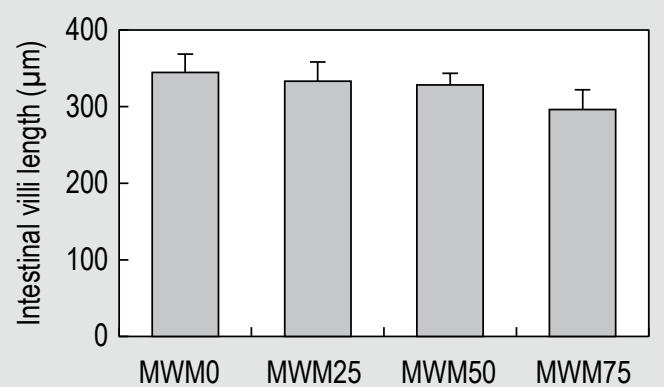

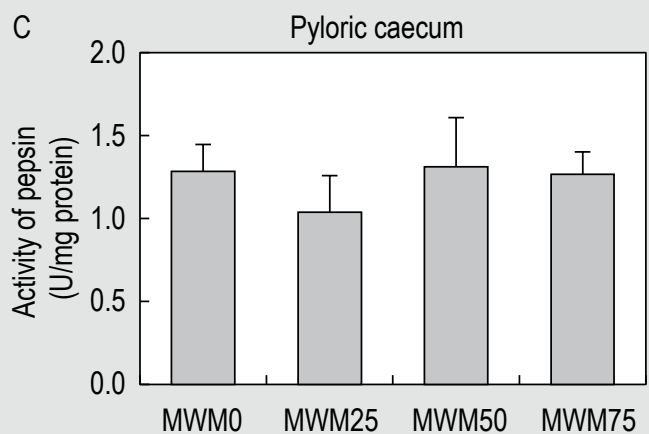

Figure 1. (Continued) (B) the length of proximal intestinal villi; (C) the activity of pepsin in the pyloric caecum. Data are shown as means \pm standard error $(S E)(n=6)$.

\section{Lipid metabolism in the liver}

Lipid content in the liver increased in MWM75 $(P<0.05)$ compared with that in the control group (Figure 2A). Fatty acid synthase (FAS), and acetyl-CoA carboxylase (ACC) are two key enzymes involved in lipid synthesis. Liver FAS levels in the MWM75 group were higher $(P<0.05)$ than those in the MWM0, MWM25, and MWM50 groups (Figure 2B).

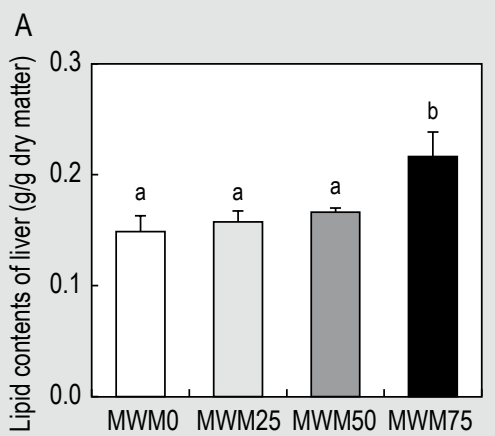

B

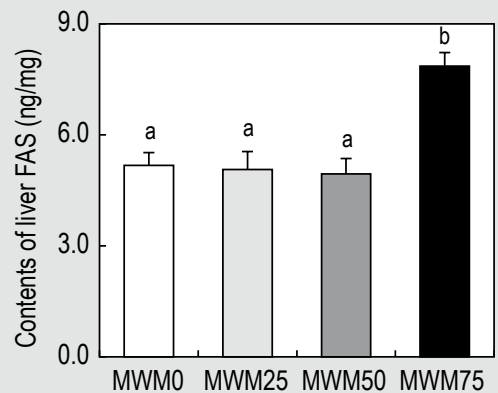

C

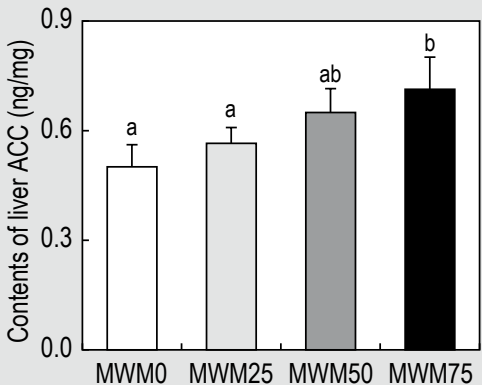

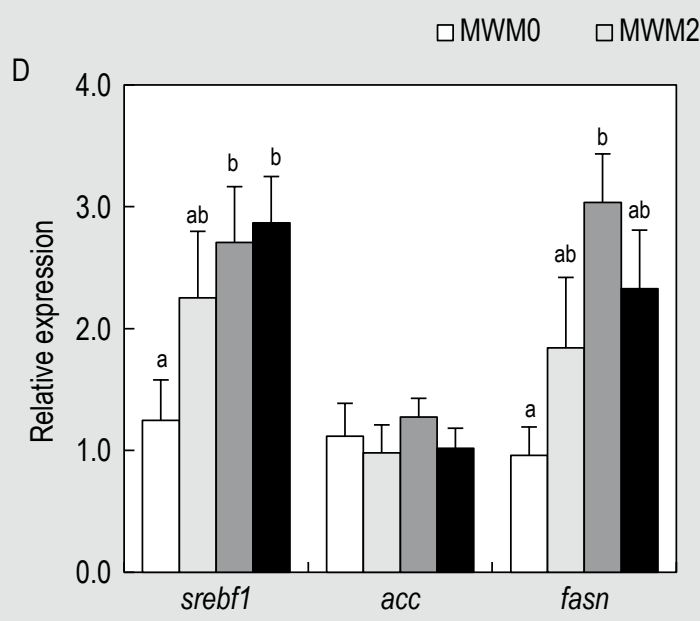

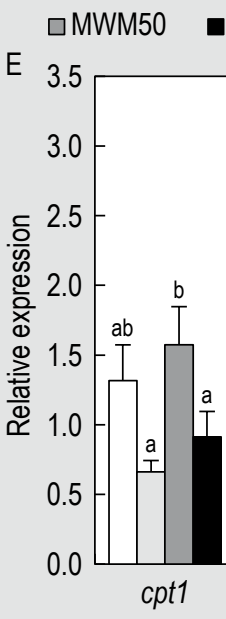

MWM75

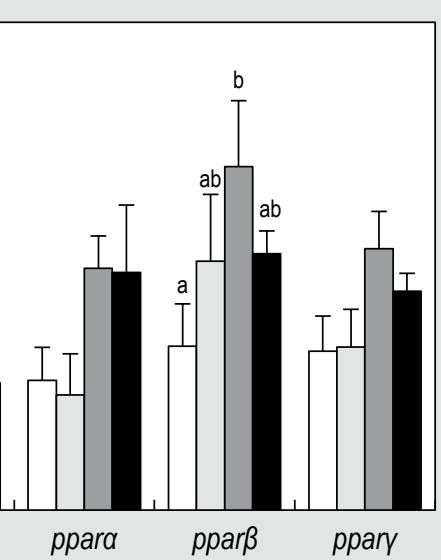

Figure 2. Lipid accumulation in the liver of largemouth bass fed diets with different levels of mealworm meal (MWM). (A) liver lipid content; (B) liver fatty acid synthase (FAS) content; (C) liver acetyl-CoA carboxylase (ACC) content; (D) the transcriptional level of sterol regulatory element binding protein 1 (srebf1), acetyl-CoA carboxylase (acc), fatty acid synthase (fasn) in the liver; (E) the transcriptional level of carnitine palmitoyl transferase 1 (cpt1), peroxisome proliferator activated receptor $\alpha$ (ppara), peroxisome proliferator activated receptor $\beta$ (ppar $\beta$ ), and peroxisome proliferator activated receptor $y$ (ppary) in liver. Data are shown as means \pm standard error $(S E)(n=6)$. Bars assigned different superscripts are significantly different $(P<0.05)$. 
The liver ACC content in the MWM75 group was higher $(P<0.05)$ than that in the MWM0 and MWM25 groups (Figure 2C). Srebf1 is a key transcriptional control factor in adipogenesis. The mRNA level of srebf1 was higher $(P<0.05)$ in the MWM50 and MWM75 groups than in the MWM0 group. The transcriptional level of fasn was upregulated $(P<0.05)$ in the liver of the MWM50 group compared to the MWM0 group, as was the relative expression of ppar $\beta$ (Figure 2D and Figure 2E). The relative mRNA level of $c p t 1$ was increased in MWM25 and MWM75 $(P<0.05)$ (Figure $2 \mathrm{E})$. The transcriptional levels of acc, ppara, and ppary were not affected by dietary MWM $(P>0.05)$ (Figure 2D and $2 \mathrm{E}$ ).

\section{Histological analysis of liver}

Histological results of the liver are shown in Figure 3A. In MWM0, the structure of liver tissue was normal, the boundary of hepatocytes was clear, and there was no obvious
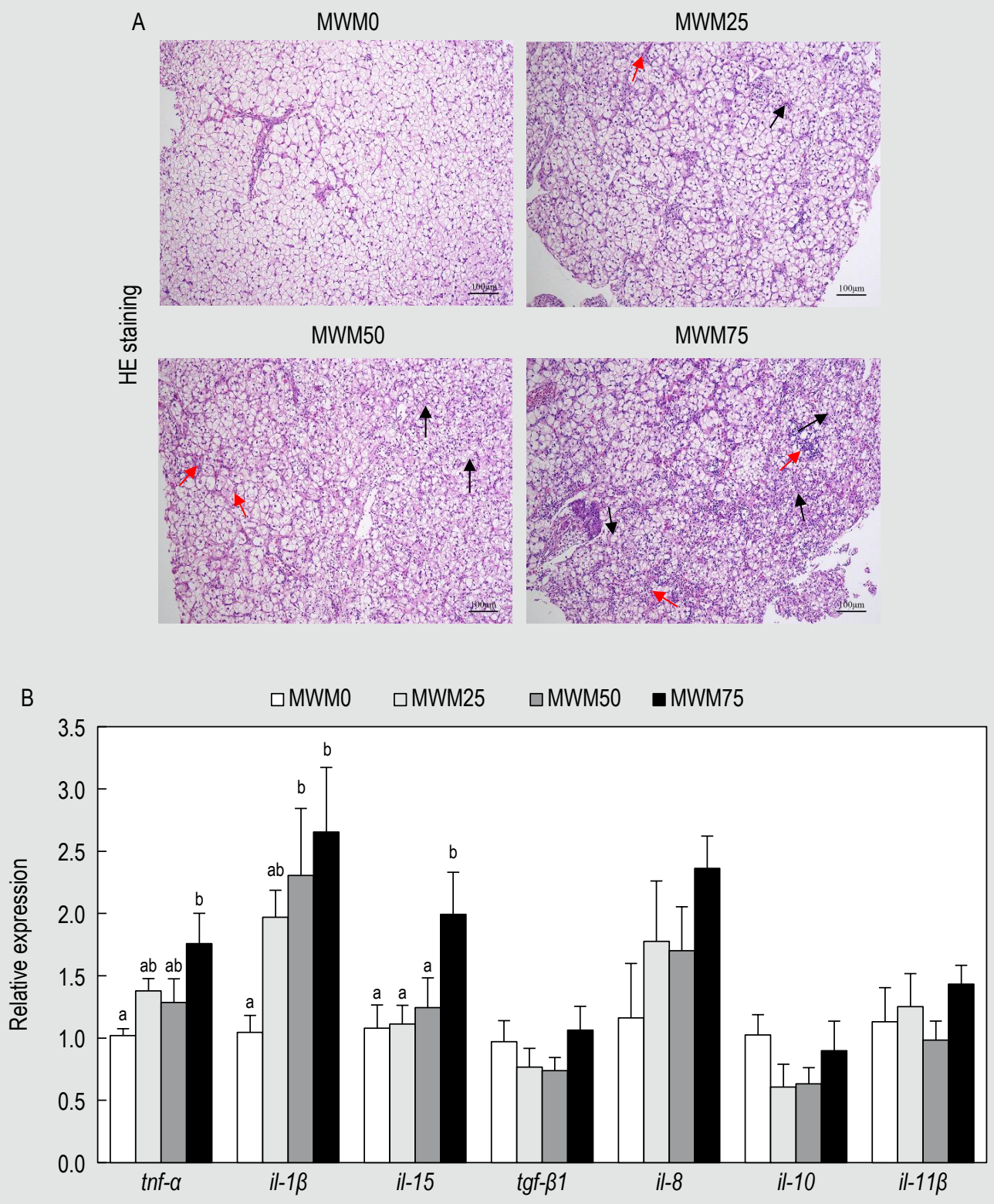

Figure 3. The histology of liver and relative mRNA levels of inflammation of liver in largemouth bass fed diets containing graded levels of mealworm meals (MWM). (A) haematoxylin-eosin (H\&E) staining of liver; the hepatocytes are necrotic and degenerative, the cell outline has disappeared, and the nucleus is fragmented, as shown by the black arrow; eosinophils can be seen in the tissue, as shown by the red arrow (eosinophilic granulocyte). (B) the relative mRNA levels of tumour necrosis factor $\alpha$ (tnf- $\alpha$ ), interleukin $1 \beta$

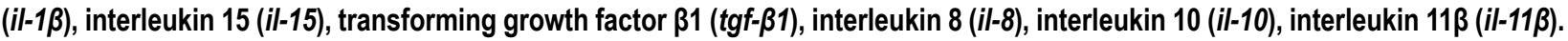
Data are shown as means \pm standard error $(S E)(n=6)$. Bars assigned different superscripts are significantly different $(P<0.05)$. 
degeneration. No obvious inflammatory cell infiltration was observed in the liver of MWM0. In MWM25, the structure of the liver tissue was slightly abnormal. There were a small number of necrotic hepatocytes (with a black arrow), and eosinophils could be seen in the liver (with a red arrow). In the MWM50 and MWM75 groups, the structure of liver tissue was severely abnormal, a large number of hepatocytes had degenerated, the outline disappeared, and nucleus pyknosis was evident (indicated by black arrows), and a large number of inflammatory cells infiltrated the tissue (with red arrows) (Figure 3A).

The relative expression of inflammatory cytokine genes in the largemouth liver is shown in Figure 3B. The transcriptional levels of $t n f-\alpha, i l-1 \beta$, and $i l-15$ were higher $(P<0.05)$ in the MWM75 group than in the MWM0 group (Figure 3B). However, the mRNA levels of $\operatorname{tgf}-\beta 1$, il-8, il-10, and $i l-11 \beta$ were not affected by dietary MWM $(P>0.05)$ (Figure 3B).

\section{Apoptosis of the liver}

DAPI and TUNEL assays were used to evaluate the levels of apoptotic cells. Cells in which nuclei were stained green were apoptotic cells; nuclei stained blue, as were normal cells. The number of apoptotic cells increased in the MWM50 and MWM75 groups (Figure 4A). Apoptosis was stimulated by the graded levels of MWM, as the apoptotic

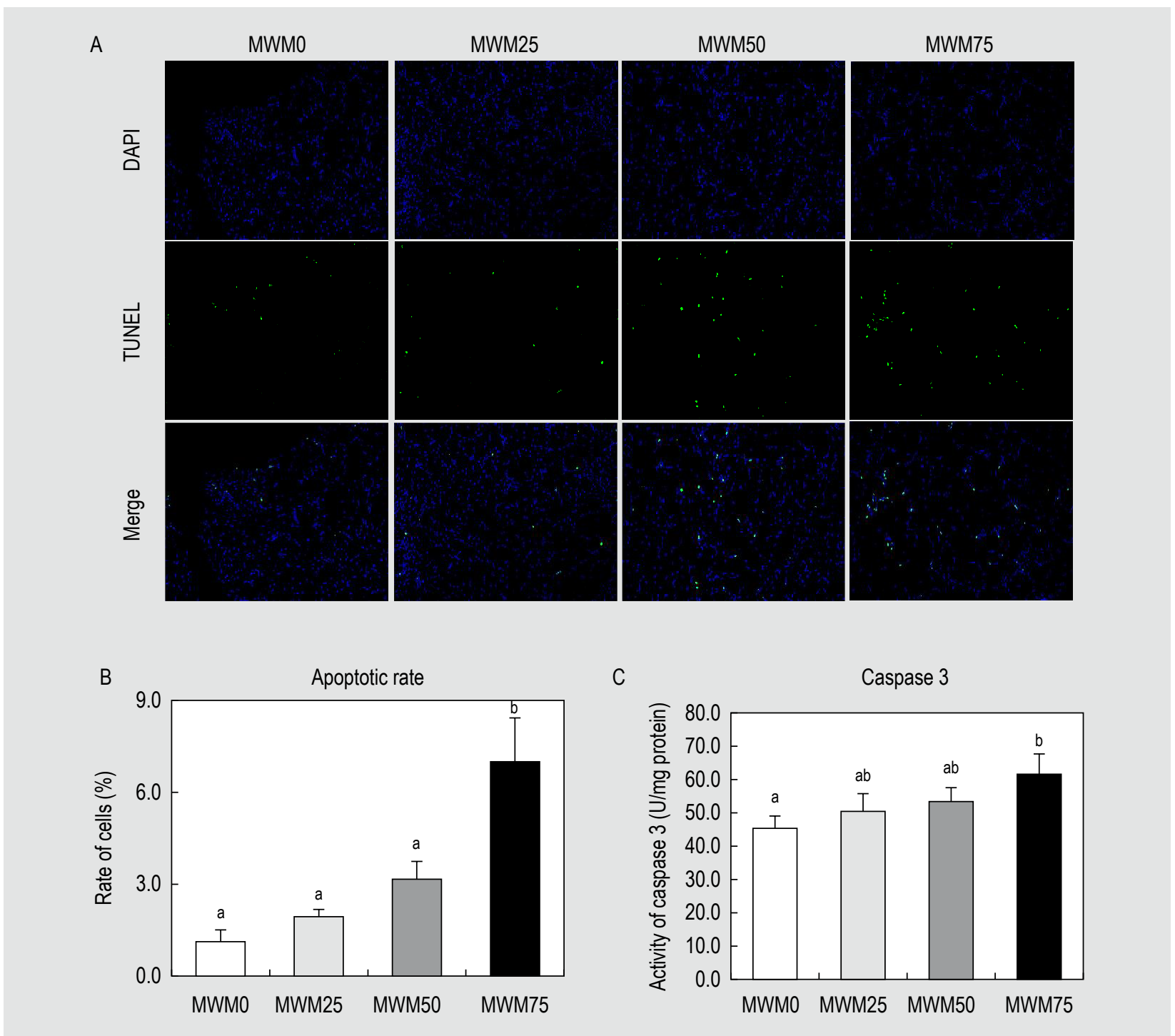

Figure 4. Liver apoptosis of largemouth bass fed diets with different levels of mealworm meal (MWM). (A) DAPI and TUNEL staining of the liver; blue fluorescence indicates normal cells and green fluorescence indicates apoptotic cells; (B) rate of apoptotic hepatocytes, apoptotic rate $(\%)=$ green area/blue area $\times 100 \%$; $(C)$ the activity of caspase 3 of liver tissue. Data are shown as means \pm standard error $(\mathrm{SE})(\mathrm{n}=6)$. Bars assigned different superscripts are significantly different $(P<0.05)$. 


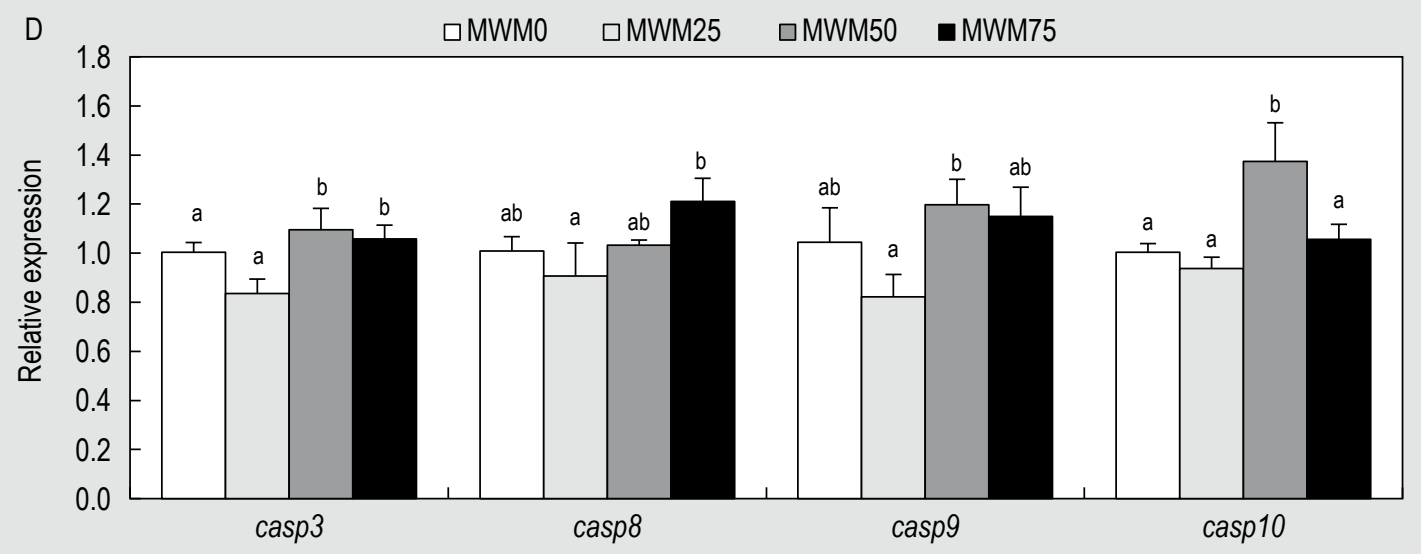

Figure 4. (Continued) (D) the relative mRNA levels of caspase 3 (casp3), casp8, casp9, casp10 of liver tissue. Data are shown as means \pm standard error $(\mathrm{SE})(\mathrm{n}=6)$. Bars assigned different superscripts are significantly different $(P<0.05)$.

rate was higher $(P<0.05)$ in MWM75 than in the other groups (Figure 4B). The activity of caspase 3 in MWM75 was higher $(P<0.05)$ than that in the control group (Figure $4 \mathrm{C})$. Compared to the control group, the relative mRNA levels of casp 3 were upregulated $(P<0.05)$ in the MWM50 and MWM75 groups. The transcriptional level of casp 8 in the MWM75 group was higher than that in the MWM25 group $(P<0.05)$ but not in the MWM50 group $(P>0.05)$. The transcriptional level of casp 9 in the MWM50 group was higher than that in the MWM25 group $(P<0.05)$ but not in the MWM75 group $(P>0.05)$. The mRNA level of casp10 in the MWM50 group was upregulated compared to the other groups $(P<0.05)$ (Figure $4 \mathrm{D})$.

\section{Discussion}

Insect proteins have been reviewed as a potential alternative protein source in aquafeeds (Henry et al., 2015). In the present study, replacing more than $50 \%$ of FM with MWM in diet (the content of mealworm meal was $20.70 \%$ ) had a negative effect on growth performance of largemouth bass. A similar result was found that body mass and weight gain were significantly decreased with the inclusion of MWM $(20 \%)$ in the diets of sea trout (Hoffmann et al., 2020). However, in the present study, 25\% replacement of FM with MWM (the content of mealworm meal was 10.35\%) had no significant negative effects on growth performance (FBW, WGR, SGR) of largemouth bass. This result concurs with a previous study showing that dietary inclusion of $25 \%$ mealworm meal did not affect the final body weight of rainbow trout (Belforti et al., 2015). The replacement of $25 \%$ of fishmeal with MWM also had no significant effect on the growth performance of blackspot sea bream (Iaconisi et al., 2017). The present results of growth performance were also supported by the fact that high dietary inclusion (50\%) of MWM significantly decreased final body weight, SGR, and FR, but low dietary inclusion of $20 \%$ mealworm meal in the diet did not substantially change the growth performance of European sea bass (Gasco et al., 2016).

Decreased growth and impaired feed utilisation in fish fed diets with graded levels of insect meal could be caused by an increase in indigestible non-starch polysaccharides such as chitin (Alegbeleye et al., 2012). As reported by Dylan et al. (2019), the poor growth performance of black sea bass (Centropristis striata) fed diets with high inclusion of MWM could be caused by the high levels of dietary chitins. In the present study, decreased growth performance was also reported with increasing dietary inclusion of MWM, which could be due to the increase in chitins. We also found that diets in which FM was replaced by more than $50 \%$ by MWM could cause mild epithelial sloughing off in the proximal intestine of largemouth bass. Intestinal injury could be one of the reasons for the poor growth performance of largemouth bass fed with high dietary MWM inclusions. Decreased growth performance caused by histological damage to fish intestines has also been reported in studies on tiger puffer (Takifugu rubripes) (Lim et al., 2011), gilthead sea bream (Kokou et al., 2012), and sharpsnout sea bream (Diplodus puntazzo) (Ferrara et al., 2015) where fish meal was replaced by high levels of soybean meal.

In the present study, liver damage in largemouth bass was induced by high dietary MWM. H\&E staining showed that high dietary MWM increased the number of inflammatory cells in the liver. As indicated by TUNEL staining, a distinct increase in the apoptosis rate of hepatocytes was observed in the high dietary MWM groups. Similar to the present study, histopathological changes were also found in the liver tissues of red hybrid tilapia (Oreochromis sp.) that were fed diets including graded levels of house crickets (Acheta domesticus) meal (Seong et al., 2008). Mild hepatic necrosis of the liver has also been reported in juvenile 
Jian carp (Cyprinus carpio var. Jian) fed diets with high levels of defatted black soldier fly meal (Li et al., 2017). In the present study, liver damage was also confirmed by increasing the transcription levels of casp3, casp8, casp9, and casp10 in the high dietary MWM groups. Similarly, the caspase 3 activity of MWM75 was also significantly increased. These results indicate that cell apoptosis was strongly induced by high dietary MWM intake. In general, nutritional deprivation, such as fasting, can induce apoptosis in fish (Fu et al., 2017; Xu et al., 2020). A previous study reported that in juvenile grass carp, dietary soybean $\beta$-conglycinin could induce apoptosis, and suppress growth (Duan et al., 2019). Intestinal injury resulted in a decrease in feed utilisation (feed efficiency was significantly decreased in MWM75) of largemouth bass, and the poor nutritional status could be one reason for induced apoptosis in MWM75. TNF- $\alpha$ is a cytokine with an inflammation-mediating activity. It was reported that crayfish (Cherax cainii) fed diets supplemented with black soldier fly significantly upregulated the relative expression of $t n f-\alpha$ and $i l-1 \beta$ (Foysal et al., 2019). It was also suggested that mirror carp (C. carpio) fed diets with FM replaced by a fermented meal mixture of silkworm pupae, rapeseed, and wheat exhibited significant upregulation of hepatic $\operatorname{tnf}-\alpha$ (Zhou et al., 2017). In line with these findings, the results of the relative expression of $t n f-\alpha, i l-1 \beta$, and $i l-15$ in the present study were induced by high dietary MWM, indicating induced inflammation in the liver of largemouth bass. These results indicate that decreased growth performance caused by high inclusions of dietary MWM could be partly explained by liver injury in the fish.

In the present study, the crude protein and lipid contents were not influenced by the dietary inclusion of mealworm meal. Unchanged body composition was also reported in rainbow trout (Jeong et al., 2020), European sea bass (Gasco et al., 2016), blackspot sea bream (Iaconisi et al., 2017), and mirror carp (Gümüş, 2011; Xu et al., 2018) when fish were fed with insect meal diets. However, these results did not agree with the results in rainbow trout, where the crude protein content of fish increased with increasing levels of dietary MWM (Belforti et al., 2015). In another study on Jian carp, the crude lipid content of the hepatopancreas decreased significantly as the amount of defatted black soldier fly increased (Li et al., 2017). In addition, a study in rainbow trout showed that a decrease in crude lipid content in fish filets was associated with high dietary levels of insect meal (Sealey, 2011). However, in the present study, the liver crude lipid content of largemouth bass was significantly increased in the MWM75 group. The same result was also reported in African catfish fed diets containing graded levels of mealworm meal ( $\mathrm{Ng}$ et al., 2001). FAS and ACC are two key enzymes involved in lipid synthesis, and sterol regulatory element-binding protein 1c (srebf1c) is a key transcription factor that controls lipogenesis (Sekiya et al., 2008). Previous studies in mice have shown that inflammation can induce lipid accumulation in the liver via a TNF-a induced increase in srebf1 and fas (Wei et al., 2016). In the present study, histological results indicated that high dietary MWM induced an increase in inflammation in the liver of the MWM75 group, and the relative expression of TNF- $\alpha$ also increased in MWM75. The transcription levels of srebf1 were induced by high dietary MWM (MWM50 and MWM75). Simultaneously, fas mRNA levels were stimulated. Therefore, the deposition of hepatic lipids could be caused by the activated lipogenesis in high MWM groups, which had significantly higher liver FAS and ACC contents than the control group. These results imply that high dietary MWM might improve the process of lipogenesis and increase hepatic lipid accumulation, and these results could be explained by the increasing inflammation.

In summary, MWM can replace up to $25 \%$ FM in the diets of largemouth bass without negative effects on growth, feed utilisation, and body composition. However, high dietary inclusion of MWM ( $>50 \%$ replacement of FM) will have a negative influence on growth, feed utilisation, and liver health of largemouth bass. The decreased growth performance in the high MWM groups could be partly due to liver injury through enhanced inflammation and apoptosis.

\section{Acknowledgements}

This work was funded by the National Key R\&D Program of China (2018YFD0900400), China Agriculture Research System (CARS-46), National Natural Science Foundation of China (31672670, 31972771, 31972805), Southern Marine Science and Engineering Guangdong Laboratory (Zhanjiang) (ZJW-2019-06), Fund Project of the State Key Laboratory of Freshwater Ecology and Biotechnology (2019FBZ02, 2019FBZ05), Hubei High-tech Innovation and Business Incubation Center (2019-02-055) and Science and Technology Project of Wuhan (2019020701011459). The authors are grateful to Guanghan Nie for his technical assistance.

\section{Conflict of interest}

The authors declare that the research was conducted in the absence of any commercial or financial relationships that could be construed as a potential conflict of interest.

\section{References}

Alegbeleye, W.O., Obasa, S.O., Olude, O.O., Otubu, K. and Jimoh, W., 2012. Preliminary evaluation of the nutritive value of the variegated grasshopper (Zonocerus variegatus L.) for African catfish Clarias gariepinus (Burchell. 1822) fingerlings. Aquaculture Research 43: 412-420. https://doi.org/10.1111/j.1365-2109.2011.02844.x 
Association of Official Analytical Chemists (AOAC), 2003. Official methods of analysis. AOAC, Rockville, MD, USA.

Belforti, M., Gai, F., Lussiana, C., Renna, M., Malfatto, V., Rotolo, L., Marco, M.D., Dabbou, S., Schiavone, A. and Zoccarato, I., 2015. Tenebrio molitor meal in rainbow trout (Oncorhynchus mykiss) diets: effects on animal performance, nutrient digestibility and chemical composition of fillets. Italian Journal of Animal Science 17: 363-369. https://doi.org/10.4081/ijas.2015.4170

Bustin, S.A., Benes, V., Garson, J.A., Hellemans, J., Huggett, J., Kubista, M., Mueller, R., Nolan, T., Pfaffl, M.W., Shipley, G.L., Vandesompele, J. and Wittwer, C.T., 2009. The MIQE guidelines: minimum information for publication of quantitative real-time PCR experiments. Clinical Chemistry 55: 611-622. https://doi. org/10.1373/clinchem.2008.112797

Duan, X.D., Feng, L., Jiang, W.D., Wu, P., Liu, Y., Kuang, S.Y., Tang, L., Tang, W.N., Zhang, Y.A. and Zhou, X.Q., 2019. Dietary soybean $\beta$-conglycinin suppresses growth performance and inconsistently triggers apoptosis in the intestine of juvenile grass carp (Ctenopharyngodon idella) in association with ROS-mediated MAPK signalling. Aquaculture Nutrition 25: 770-782. https://doi. org/10.1111/anu.12895

Ferrara, E., Gustinelli, A., Fioravanti, M.L., Restucci, B., Quaglio, F., Marono, S. and Piccolo, G., 2015. Histological and micro-/macromorphological evaluation of intestine in sharpsnout seabream (Diplodus puntazzo) fed soybean meal-based diets added with MOS and inulin as prebiotics. Aquaculture International 23: 1525-1537. https://doi.org/10.1007/s10499-015-9902-y

Foysal, M.J., Nguyen, T.T.T., Chaklader, M.R., Siddik, M.A.B., Tay, C.Y., Fotedar, R. and Gupta, S.K., 2019. Marked variations in gut microbiota and some innate immune responses of fresh water crayfish, marron (Cherax cainii, Austin 2002) fed dietary supplementation of Clostridium butyricum. PeerJ 7: 7553. https:// doi.org/10.7717/peerj.7553

Fu, Y.F., Liu, X., Gao, M., Zhang, Y.N. and Liu, J., 2017. Endoplasmic reticulum stress induces autophagy and apoptosis while inhibiting proliferation and drug resistance in multiple myeloma through the PI3K/Akt/mTOR signaling pathway. Oncotarget 8: 61093-61106. https://doi.org/10.18632/oncotarget.17862

Gasco, L., Henry, M., Piccolo, G., Marono, S., Gai, F., Renna, M., Lussiana, C., Antonopoulou, E., Mola, P. and Chatzifotis, S., 2016. Tenebrio molitor meal in diets for European sea bass (Dicentrarchus labrax L.) juveniles: growth performance, whole body composition and in vivo apparent digestibility. Animal Feed Science and Technology 220: 34-45. https://doi.org/10.1016/j. anifeedsci.2016.07.003

Gümüş, E., 2011. Effect of replacement of fishmeal with sand smelt (Atherina boyeri) meal on growth, feed utilization and body composition of mirror carp fry (Cyprinus carpio). Kafkas Üniversitesi Veteriner Fakültesi Dergisi 17: 363-369. https://doi. org/10.9775/kvfd.2010.3418

Harikrishnan, R., Kim, J.-S., Balasundaram, C. and Heo, M.-S., 2012. Dietary supplementation with chitin and chitosan on haematology and innate immune response in Epinephelus bruneus against Philasterides dicentrarchi. Experimental Parasitology 131: 116124. https://doi.org/10.1016/j.exppara.2012.03.020
Henry, M., Gasco, L., Piccolo, G. and Fountoulaki, E., 2015. Review on the use of insects in the diet of farmed fish: past and future. Animal Feed Science and Technology 203: 1-22. https://doi.org/10.1016/j. anifeedsci.2015.03.001

Henry, M.A., Gai, F., Enes, P., Perez-Jimenez, A. and Gasco, L., 2018. Effect of partial dietary replacement of fishmeal by yellow mealworm (Tenebrio molitor) larvae meal on the innate immune response and intestinal antioxidant enzymes of rainbow trout (Oncorhynchus mykiss). Fish and Shellfish Immunol 83: 308-313. https://doi. org/10.1016/j.fsi.2018.09.040

Hoffmann, L., Rawski, M., Nogales-Merida, S. and Mazurkiewicz, J., 2020. Dietary inclusion of Tenebrio molitor meal in sea trout larvae rearing: effects on fish growth performance, survival, condition, and GIT and liver enzymatic activity. Annals of Animal Science 20: 579-598. https://doi.org/10.2478/aoas-2020-0002

Iaconisi, V., Marono, S., Parisi, G., Gasco, L., Genovese, L., Maricchiolo, G., Bovera, F. and Piccolo, G., 2017. Dietary inclusion of Tenebrio molitor larvae meal: effects on growth performance and final quality treats of blackspot sea bream (Pagellus bogaraveo). Aquaculture 476: 49-58. https://doi.org/10.1016/j.aquaculture.2017.04.007

Jeong, S.-M., Khosravi, S., Mauliasari, I.R. and Lee, S.-M., 2020. Dietary inclusion of mealworm (Tenebrio molitor) meal as an alternative protein source in practical diets for rainbow trout (Oncorhynchus mykiss) fry. Fisheries and Aquatic Sciences 23. https://doi. org/10.1186/s41240-020-00158-7

Kokou, F., Rigos, G., Henry, M., Kentouri, M. and Alexis, M., 2012. Growth performance, feed utilization and non-specific immune response of gilthead sea bream (Sparus aurata L.) fed graded levels of a bioprocessed soybean meal. Aquaculture 364-365: 7481. https://doi.org/10.1016/j.aquaculture.2012.08.009

Li, S., Ji, H., Zhang, B., Zhou, J. and Yu, H., 2017. Defatted black soldier fly (Hermetia illucens) larvae meal in diets for juvenile Jian carp (Cyprinus carpio var. Jian): growth performance, antioxidant enzyme activities, digestive enzyme activities, intestine and hepatopancreas histological structure. Aquaculture 477: 62-70. https://doi.org/10.1016/j.aquaculture.2017.04.015

Lim, S.J., Kim, S.S., Ko, G.Y., Song, J.W., Oh, D.H., Kim, J.D., Kim, J.U. and Lee, K.J., 2011. Fish meal replacement by soybean meal in diets for Tiger puffer, Takifugu rubripes. Aquaculture 313: 165-170. https://doi.org/10.1016/j.aquaculture.2011.01.007

Lindsay, G.J.H., Walton, M.J., Adron, J.W., Fletcher, T.C., Cho, C.Y. and Cowey, C.B., 1984. The growth of rainbow trout (Salmo gairdneri) given diets containing chitin and its relationship to chitinolytic enzymes and chitin digestibility. Aquaculture 37: 315-334. https:// doi.org/10.1016/0044-8486(84)90297-7

Loh, J.Y., Mousavi, S. and Zahedinezhad, S., 2020. A review on insect meals in aquaculture: the immunomodulatory and physiological effects. International Aquatic Research 12: 100-115. https://doi. org/10.22034/IAR(20).2020.1897402.1033

Lu, D.L., Ma, Q., Wang, J., Li, L.Y., Han, S.L., Limbu, S.M., Li, D.L., Chen, L.Q., Zhang, M.L. and Du, Z.Y., 2019. Fasting enhances cold resistance in fish through stimulating lipid catabolism and autophagy. Journal of Physiology 597: 1585-1603. https://doi. org/10.1113/JP277091 
Ng, W., Liew, F., Ang, L. and Wong, K., 2001. Potential of mealworm (Tenebrio molitor) as an alternative protein source in practical diets for African catfish, Clarias gariepinus. Aquaculture Research 32: 273-280. https://doi.org/10.1046/j.1355-557x.2001.00024.x

Piccolo, G., Iaconisi, V., Marono, S., Gasco, L., Loponte, R., Nizza, S., Bovera, F. and Parisi, G., 2017. Effect of Tenebrio molitor larvae meal on growth performance, in vivo nutrients digestibility, somatic and marketable indexes of gilthead sea bream (Sparus aurata). Animal Feed Science and Technology 226: 12-20. https://doi.org/10.1016/j. anifeedsci.2017.02.007

Redmen, D., Nelson, D.A., Roy, J., Goldberg, R., Scott, T.M., Rust, M.B. and Mercaldo-Allen, R., 2019. A pilot study using graded yellow mealworm (Tenebrio molitor) meal in formulated diets for growth performance of black sea bass (Centropristis striata). NOAA Technical Memo NMFS-NE-253. US Department of Commerce, Woods Hole, MA, USA.

Rumpold, B.A. and Schlüter, O.K., 2013a. Potential and challenges of insects as an innovative source for food and feed production. Innovative Food Science and Emerging Technologies 17: 1-11. https://doi.org/10.1016/j.ifset.2012.11.005

Rumpold, B.A. and Schlüter, O.K., 2013b. Nutritional composition and safety aspects of edible insects. Molecular Nutrition and Food Research 57: 802-823. https://doi.org/10.1002/mnfr.201200735

Sankian, Z., Khosravi, S., Kim, Y.-O. and Lee, S.-M., 2018. Effects of dietary inclusion of yellow mealworm (Tenebrio molitor) meal on growth performance, feed utilization, body composition, plasma biochemical indices, selected immune parameters and antioxidant enzyme activities of mandarin fish (Siniperca scherzeri) juveniles. Aquaculture 496: 79-87. https://doi.org/10.1016/j. aquaculture.2018.07.012

Sealey, W.M., 2011. Sensory analysis of rainbow trout, Oncorhynchus mykiss, fed enriched back soldier fly prepupae, Hermetia illucens. Journal of the World Aquaculture Society 42: 34-45. https://doi. org/10.1111/j.1749-7345.2010.00441.x

Sekiya, M., Hiraishi, A., Touyama, M. and Sakamoto, K., 2008. Oxidative stress induced lipid accumulation via SREBP1c activation in HepG2 cells. Biochemical and Biophysical Research Communications 375: 602-607. https://doi.org/10.1016/j.bbrc.2008.08.068

Seong, W.L., Huan, C.T., Wee, W. and Zahari, M.W., 2008. The effect of house cricket (Acheta domesticus) meal on growth performance of red hybrid tilapia (Oreochromis sp.). International Journal of Aquatic Science 8: 78-82.

Su, J., Gong, Y., Cao, S., Lu, F., Han, D., Liu, H., Jin, J., Yang, Y., Zhu, X. and Xie, S., 2017. Effects of dietary Tenebrio molitor meal on the growth performance, immune response and disease resistance of yellow catfish (Pelteobagrus fulvidraco). Fish and Shellfish Immunology 69: 59-66. https://doi.org/10.1016/j.fsi.2017.08.008
Su, J., Gong, Y., Mei, L., Xi, L., Chi, S., Yang, Y., Jin, J., Liu, H., Zhu, X., Xie, S. and Han, D., 2020. The characteristics of glucose homeostasis in grass carp and Chinese longsnout catfish after oral starch administration: a comparative study between herbivorous and carnivorous species of fish. British Journal of Nutrition 123: 627641. https://doi.org/10.1017/S0007114519003234

Sun, J.L., Zhao, L.L., Liao, L., Tang, X.H., Cui, C., Liu, Q., He, K., Ma, J.D., Jin, L., Yan, T., Zhou, J. and Yang, S., 2019. Interactive effect of thermal and hypoxia on largemouth bass (Micropterus salmoides) gill and liver: aggravation of oxidative stress, inhibition of immunity and promotion of cell apoptosis. Fish and Shellfish Immunology 98: 923-936. https://doi.org/10.1016/j.fsi.2019.11.056

Tang, Q., 2012. Regulatory effects of Tenebrio molitor Linnaeus on immunological function in mice. African Journal of Biotechnology 11: 8348-8352. https://doi.org/10.5897/AJB12.340

Wei, J., Zhen, Y.Z., Cui, J., He, F.L., Shen, T., Hu, G., Ren, X.H. and Lin, Y.J., 2016. Rhein lysinate decreases inflammation and adipose infiltration in kk/hlj diabetic mice with non-alcoholic fatty liver disease. Archives of Pharmacal Research 39: 960-969. https://doi. org/10.1007/s12272-016-0770-4

Xie, S., Yin, P., Tian, L., Liu, Y. and Niu, J., 2020. Lipid metabolism and plasma metabolomics of juvenile largemouth bass micropterus salmoides were affected by dietary oxidized fish oil. Aquaculture 522: 3. https://doi.org/10.1016/j.aquaculture.2020.735158

Xu, W., Li, H., Wu, L., Dong, B., Jin, J., Han, D., Zhu, X., Yang, Y., Liu, H. and Xie, S., 2020. Genetically based physiological responses to overwinter starvation in gibel carp (Carassius gibelio). Frontiers in Endocrinology 11: 578777. https://doi.org/10.3389/ fendo.2020.578777

Xu, X., Ji, H., Yu, H. and Zhou, J., 2018. Influence of replacing fish meal with enzymatic hydrolysates of defatted silkworm pupa (Bombyx mori L.) on growth performance, body composition and non-specific immunity of juvenile mirror carp (Cyprinus carpio var. specularis). Aquaculture Research 49: 1480-1490. https://doi. org/10.1111/are.13603

Yu, H., Zhang, L., Chen, P., Liang, X., Cao, A., Han, J., Wu, X., Zheng, Y., Qin, Y. and Xue M., 2019. Dietary bile acids enhance growth, and alleviate hepatic fibrosis induced by a high starch diet via AKT/FOXO1 and cAMP/AMPK/SREBP1 pathway in Micropterus salmoides. Frontier in Physiology 10: 1430. https://doi.org/10.3389/ fphys.2019.01430

Yu, L.L., Yu, H.H., Liang, X.F., Li, N., Wang, X., Li, F.H., Wu, X.F., Zheng, Y.H., Xue, M. and Liang, X.F., 2018. Dietary butylated hydroxytoluene improves lipid metabolism, antioxidant and antiapoptotic response of largemouth bass (Micropterus salmoides). Fish and Shellfish Immunology 72: 220-229. https://doi.org/10.1016/j. fsi.2017.10.054

Zhou, J.S., Chen, Y.S., Ji, H. and Yu, E.M., 2017. The effect of replacing fish meal with fermented meal mixture of silkworm pupae, rapeseed and wheat on growth, body composition and health of mirror carp (Cyprinus carpio var. Specularis). Aquaculture Nutrition 23: 741754. https://doi.org/10.1111/anu.12441 
